\title{
Penentuan Peak Kilovoltage (kVp) Pesawat Sinar-X Dengan Pemanfaatan Imaging Plate (IP) Di RSUD Dr. Moewardi
}

\author{
Bibit Cahyani ${ }^{*}$, Utari ${ }^{1}$ dan Muhtarom ${ }^{2}$ \\ ${ }^{1}$ Program Studi Fisika, Fakultas MIPA, Universitas Sebelas Maret, Surakarta \\ ${ }^{2}$ RSUD Dr.Moewardi, Surakarta \\ "bibitcahyani@gmail.com
}

Received 06-11-2020, Revised 02-03-2021, Accepted 11-07-2021, Published 01-10-2021

\begin{abstract}
Research has been carried out to determine the $\mathrm{kVp}$ of X-ray aircraft using an imaging plate (IP) as a measuring tool. The imaging plate functions to record images after irradiation and as a detector to capture and store X-ray energy when it penetrates an object. The purpose of this study is to use IP as a $\mathrm{kVp}$ measurement tool. The method used is to create a characteristic curve of the relationship between the ratio of Region of Interest (ROI) of two aluminum filters to rated voltage $(\mathrm{kVp})$. From the research obtained the equation $\mathrm{y}=2816.61 \mathrm{x}^{2}-4532.19 \mathrm{x}+$ 1878.65 with $\mathrm{R}^{2}=0.988$. The $\mathrm{kVp}$ test was carried out using a fluoroscopic X-ray model SM$20 \mathrm{HFH}$. The test results obtained that the measured $\mathrm{kVp}$ value at a voltage of $70 \mathrm{kV}$ was 66.21 $\mathrm{kV}$ and an error value of $5.41 \%$. While the measured $\mathrm{kVp}$ value at $55 \mathrm{kV}$ is $58.95 \mathrm{kV}$ with an error value of $-7.18 \%$. These results indicate that IP can be used to measure $\mathrm{kVp}$ with an error below the allowable tolerance, namely the max error $\leq$ of $10 \%$.
\end{abstract}

Keywords: imaging plate (IP), image, ROI, X-rays, $\mathrm{kVp}$

\section{ABSTRAK}

Telah dilakukan penelitian untuk menentukan $\mathrm{kVp}$ pesawat sinar-X dengan pemanfaatan imaging plate (IP) sebagai alat ukur. Imaging plate berfungsi untuk merekam citra setelah dilakukan penyinaran serta sebagai detektor untuk menangkap dan menyimpan energi sinar-X ketika menembus suatu objek. Tujuan dari penelitian ini adalah memanfaatkan IP sebagai alat ukur kVp. Metode yang digunakan adalah membuat kurva karakteristik hubungan antara rasio Region Of Interest (ROI) dua filter aluminium terhadap tegangan terukur $(\mathrm{kVp})$. Dari penelitian diperoleh persamaan $\mathrm{y}=2816,61 x^{2}-4532,19 x+1878,65$ dengan $\mathrm{R}^{2}=0,988$. Pengujian $\mathrm{kVp}$ dilakukan dengan menggunakan pesawat sinar-X Fluoroskopi model SM20HFH. Hasil pengujian diperoleh nilai $\mathrm{kVp}$ yang terukur pada tegangan $70 \mathrm{kV}$ adalah 66,21 $\mathrm{kV}$ dan nilai error $5,41 \%$. Sedangkan nilai $\mathrm{kVp}$ yang terukur pada tegangan $55 \mathrm{kV}$ adalah $58,95 \mathrm{kV}$ dengan nilai error $-7,18 \%$. Hasil ini menunjukkan bahwa IP dapat digunakan untuk mengukur $\mathrm{kVp}$ dengan kesalahan di bawah toleransi yang diperbolehkan yakni error max $\leq$ $10 \%$.

Kata kunci : imaging plate (IP), filter, citra, ROI, sinar-X, $\mathrm{kVp}$

\section{PENDAHULUAN}

Radiodiagnostik merupakan bagian dari sarana penegakkan diagnosa pasien dengan memanfaatkan sinar-X. Sinar-X dipancarkan ke objek pasien kemudian setelah menembus diproyeksikan ke film rontgen sehingga bayangan objek dapat diamati secara visual. Ketika dosis penyinaran yang diberikan rendah maka akan menghasilkan gambar yang sulit diamati, sedangkan bila dosis yang diberikan terlalu tinggi maka menghasilkan gambar yang gelap dan pasien akan menerima radiasi yang tidak perlu. Penyebab kesalahan pemberian dosis dalam penggunaan sinar-X adalah ketidakcocokan antara 
tegangan tabung dengan panel kontrol sinar- $X$ dan intensitas radiasi sinar- $X$ yang dihasilkan. Dengan demikian perlu dilakukan uji kesesuaian tegangan tabung menggunakan Kilovolt Peak Meter $(\mathrm{kVp})$ sebagai pengukur ${ }^{[1]}$.

Uji kesesuaian pesawat sinar-X adalah suatu tindakan untuk menetapkan pesawat sinar-X dalam kondisi handal untuk kegiatan radiologi diagnostik maupun intervensional sesuai dengan peraturan perundang-undangan. Uji kesesuaian dimaksudkan untuk menjamin pengoperasian pesawat sinar-X yang handal dan selamat untuk pasien, pekerja, dan masyarakat. Salah satu contoh parameter uji kesesuaian pesawat sinar-X adalah akurasi tegangan $^{[2]}$. Hasil radiografi, kualitas dan kuantitas salah satunya dipengaruhi oleh tegangan pemercepat Kilovolt $(\mathrm{kV})$. Uji akurasi $\mathrm{kVp}$ dilaksanakan sekali dalam setahun untuk memastikan pesawat sinar-X agar kinerjanya selalu dalan kondisi yang andal ${ }^{[3]}$.

Verifikasi $\mathrm{kVp}$ pesawat sinar-X dilakukan dengan mengukur tegangan tabung pesawat sinar-X. Terdapat dua metode dalam melakukan pengukuran tegangan, yakni metode invasive dan non-invasive. Metode invasive adalah metode pengukuran secara langsung pada kedua elektroda tabung pesawat sinar-X. Metode ini tidak direkomendasikan karena tidak praktis, karena tegangan pada tabung sangat tinggi sampai mencapai puluhan $\mathrm{kV}$ dan harus membuka casing tabung. Sedangkan, metode non-invasive adalah metode pengukuran tidak langsung yakni dengan mengukur radiasi yang dipancarkan oleh sinar-X menggunakan detektor misalnya piranha atau raysafe ${ }^{[4]}$.

Pengaturan $\mathrm{kVp}$ adalah salah satu faktor utama yang dapat mempengaruhi kualitas gambar dalam pencitraan sinar-X. Telah dilakukan penelitian dengan membuat alat $\mathrm{kVp}$-meter dengan mikrokontroler ATmega16 (Atmel). Penelitian ini dilakukan berdasarkan prinsip bahwa foton sinar-X yang mengenai fotodioda akan difilter oleh tembaga dengan ketebalan $0,5 \mathrm{~mm}$ dan $1 \mathrm{~mm}$, sehingga menghasilkan arus yang berbeda pula sebanding dengan rasio intensitasnya. Selama proses pemaparan, data hasil pengukuran diproses oleh alat mikrokontroler. Nilai tegangan yang terukur oleh alat ini adalah antara $60-120 \mathrm{kVp}^{[5]}$.

Penelitian lain dilakukan tentang jaminan kualitas pesawat sinar-X konvensional menggunakan alat non-invasive $\mathrm{kV}$ meter yang dilakukan di Rumah Sakit Mansoura seperti reproduksibilitas dosis keluaran, waktu, dan tegangan tinggi. Alat yang digunakan adalah solid state detectors dan ion chamber pada alat $\mathrm{kV}$ meter. Pengaturan pada akurasi $\mathrm{kV}$ dengan menggunakan arus tabung $12 \mathrm{~mA}$ untuk interval $\mathrm{kV}$ dari 50-100 kV. Hasilnya menunjukkan rata-rata kesalahan terukur tegangan tinggi berkisar 1,5-1,35\%. Nilai tersebut lebih rendah dari batas toleransi $\pm 5 \%$ menurut American Association of Physicist in Medicine ${ }^{[6]}$.

Imaging Plate (IP) adalah lembaran yang terdiri dari beberapa lapisan phosphor dan lapisan pendukung lainnya. IP berfungsi untuk menangkap dan menyimpan bayangan laten dengan memposisikannya ke dalam kaset imaging plate. IP berguna untuk menangkap gambar dari organ pasien yang diekspos sinar-X. Pembentukan citra pada IP diawali ketika organ pasien dieskpos, maka IP akan menangkap energi sinar-X dan disimpan oleh bahan fosfor dan kemudian dimasukkan ke Computed Radiography. Laser scanner akan membaca hasil eksposi dan mengubahnya ke sinyal digital yang ditampilkan pada layar monitor komputer dengan bantuan software khusus untuk medical imaging ${ }^{[7]}$.

Computed Radiography (CR) merupakan metode pencitraan radiografi yang mengubah sistem analog menjadi digital memakai photo-stimulable phosphor (PSP) untuk perolehan data dan pemrosesan dari suatu citra, sehingga ketika dilakukan perbesaran tidak mengalami perubahan ukuran dan resolusi. Data yang ditampilkan oleh CR berupa energi 
sinar-X yang tersimpan di dalam $\mathrm{IP}^{[8]}$. Plate pencitraan yang digunakan untuk membuat akuisisi gambar, merupakan plate berbasis PSP. Satu imaging plate akan digunakan untuk setiap kali eksposur. Imaging plate tertutup dalam kaset, yang hampir sama dengan kaset film layar. Selama eksposur, elektron dalam plate fosfor akan bergerak ke tingkat energi yang lebih tinggi, terperangkap dan membentuk gambar laten. Gambar laten tersebut kemudian diproses dan dengan cara meletakan imaging plate di pembaca $\mathrm{CR}$ atau disebut dengan digitizer ${ }^{[9]}$.

Berdasarkan uraian diatas, pada penelitian ini dilakukan uji kesesuaian akurasi tegangan tabung dengan metode non-invasive pada pesawat Sinar-X di RSUD Dr. Moewardi. Penelitian ini dilakukan untuk mengetahui besarnya $\mathrm{kVp}$ yang terukur dengan memanfaatkan Imaging Plate (IP) sebagai detektor. IP dan filter yang telah diekspos kemudian discan untuk membaca hasil Region Of Interest (ROI) dari kedua filter alumunium. Rasio dari ROI dan $\mathrm{kV}$ kemudian diplot pada kurva karakteristik IP. Penelitian digunakan sebagai alternatif dalam pengukuran $\mathrm{kV}$ dengan metode pengukuran tidak langsung atau non-invasive, selain menggunakan detektor piranha atau raysafe.

\section{METODE}

Alat yang digunakan dalam penelitian ini adalah pesawat sinar-X Simulator model M$1135 \mathrm{P}$ untuk menentukan kurva karakteristik imaging plate (IP), pesawat sinar-X Fluoroskopi model SM-20HFH untuk pengujian nilai kVp terukur, perangkat Imaging Plate Computed Radiogaphy (CR) berukuran $35,4 \mathrm{~cm}$ x $43 \mathrm{~cm}$ sebagai perekam citra objek yang dihasilkan dan scanner Fujifilm FCR PRIMAT2 untuk membaca IP. Bahan yang digunakan adalah filter Al dengan ketebalan $6 \mathrm{~mm}$ dan $2 \mathrm{~mm}$. Variasi tegangan yang digunakan adalah 60-100 kV dengan step $5 \mathrm{kV}$, SSD $100 \mathrm{~cm}$, dan luas lapangan penyinaran $10 \mathrm{~cm} \times 10 \mathrm{~cm}$. Dari data set kemudian diperoleh nilai ROI dari masingmasing filter dan $\mathrm{kVp}$ terukur yang kemudian dibuat grafik hubungan antara nilai rasio ROI terhadap tegangan terukur $(\mathrm{kVp})$. Dari grafik diperoleh nilai persamaan yang digunakan untuk pengujian $\mathrm{kVp}$. Tegangan yang diuji adalah $70 \mathrm{kV}$ dan $55 \mathrm{kV}$.

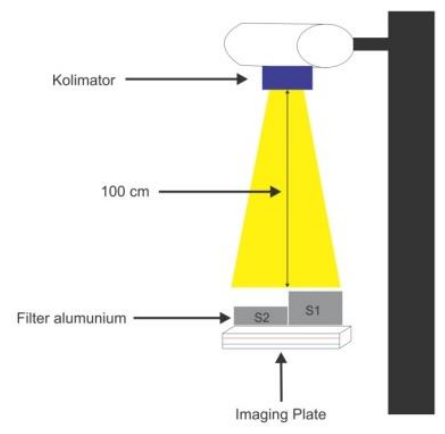

Gambar 1. Skema Penyinaran pada filter alumunium

\section{HASIL DAN PEMBAHASAN}

Penelitian telah dilakukan di Instalasi Radioterapi Rumah Sakit Dr. Moewardi, Surakarta. Penelitian diawali dengan melakukan studi literatur, pengambilan data, pengolahan data, analisis data, pembahasan, dan kesimpulan. Penelitian dilakukan dengan tiga tahap, yaitu uji akurasi tegangan tabung, analisis kurva karakteristik imaging plate (IP), dan penentuan nilai $\mathrm{kVp}$ pada imaging plate (IP). 
Penelitian pertama yaitu pengujian kesesuaian akurasi tegangan $k V p$. Pengujian ini dilakukan dengan menggunakan data sekunder uji kesesuaian akurasi tegangan $\mathrm{kVp}$ pesawat sinar-X Simulator di Rumah Sakit Dr. Moewardi, yang dilakukan pada tanggal 21 Oktober 2017. Sebagaimana dapat terlihat tabel 1. pengujian akurasi $\mathrm{kVp}$ dilakukan dengan menggunakan rentang tegangan $50-90 \mathrm{kV}$, arus penyinaran tetap $1 \mathrm{~mA}$. Nilai error maksimal yang dihasilkan 3,4\% pada tegangan $60 \mathrm{kV}$. Sedangkan nilai error minimal yang dihasilkan 2,9\% pada tegangan $80 \mathrm{kV}$. Nilai lolos uji berdasarkan Peraturan Badan Pengawas Tenaga Nuklir Republik Indonesia No. 2 Tahun 2018, syarat lolos uji dengan parameter akurasi tegangan sebesar error max $\leq 10 \%$, sedangkan berdasarkan American Association of Physicist in Medicine (AAPM) batas toleransi sebesar $\pm 5 \%$. Oleh karena itu, hasil uji pesawat sinar-X Simulator masih memenuhi syarat nilai lolos uji dan kinerja alat dalam kondisi yang handal.

Tabel 1. Data Uji Akurasi kVp

\begin{tabular}{cccc}
\hline $\mathrm{kVp}$ set & $\mathrm{kVp}$ ukur & \%Error & $\mathrm{mA}$ Auto \\
\hline 50 & 48,40 & 3,2 & 1 \\
60 & 57,93 & 3,4 & 1 \\
70 & 67,76 & 3,2 & 1 \\
80 & 77,72 & 2,9 & 1 \\
90 & 87,23 & 3,1 & 1 \\
\hline & Error max & 3,4 &
\end{tabular}

Penelitian selanjutnya yaitu pembacaan nilai ROI dari citra yang dihasilkan dengan menggunakan software DoseLab. Penyinaran dilakukan mengunakan pesawat sinar-X Simulator model M-1135P. Tegangan yang digunakan adalah $60-100 \mathrm{kV}$ dengan step $5 \mathrm{kV}$ dan dengan arus tetap $5 \mathrm{~mA}$. Semakin tinggi tegangan yang digunakan untuk penyinaran, makan daya tembus juga akan semakin besar. Berikut adalah hasil citra yang diperoleh pada penyinaran filter Al menggunakan pesawat sinar-X Simulator :

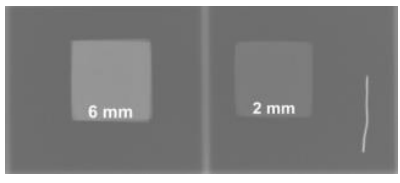

(a)

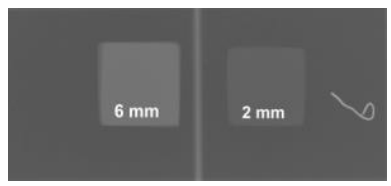

(d)

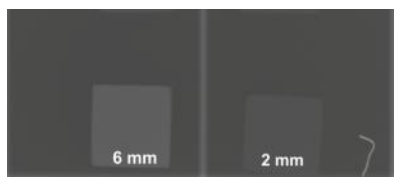

(g)

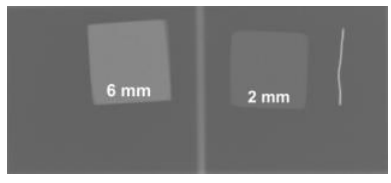

(b)

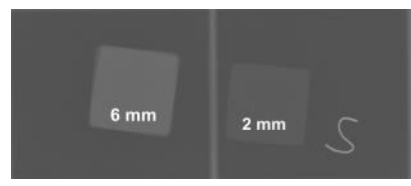

(e)

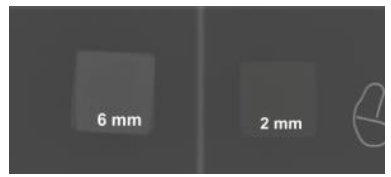

(h)

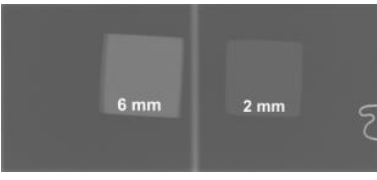

(c)

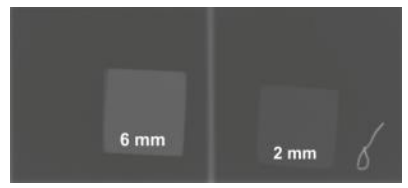

(f)

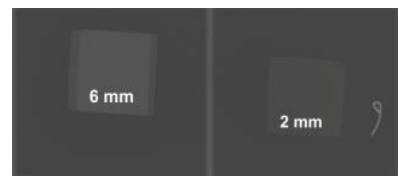

(i)

Gambar 2. Hasil citra dengan tebal filter pada penyinaran (a) $60 \mathrm{kV}$, (b) $65 \mathrm{kV}$, (c) $70 \mathrm{kV}$, (d) $75 \mathrm{kV}$, (e) $80 \mathrm{kV}$, (f) $85 \mathrm{kV}$, (g) $90 \mathrm{kV}$, (h) $95 \mathrm{kV}$, dan (i) $100 \mathrm{kV}$ dalam arus tetap $5 \mathrm{~mA}$ 
Pada gambar 2 dan 4 ditunjukkan citra yang dihasilkan pada filter dengan ketebalan $6 \mathrm{~mm}$ dan $2 \mathrm{~mm}$. Semakin tinggi tegangan, maka citra yang diperoleh akan memiliki warna yang lebih gelap dan kontrasnya akan semakin menurun. Citra yang berwarna gelap dihasilkan ketika sinar-X menembus suatu objek maka akan terjadi interaksi antara sinar-X dengan objek, sehingga sinar-X yang diserap lebih banyak, sedangkan citra berwarna terang diakibatkan karena sinar-X yang diserap lebih sedikit dibandingkan dengan sinar-X yang diteruskan.

Pengaruh ketebalan filter terhadap citra dapat dilihat dari perbedaan pola gelap terang. Filter Al dengan ketebalan $6 \mathrm{~mm}$ memiliki gambar yang lebih terang dibanding dengan tebal filter $2 \mathrm{~mm}$. Hal ini dikarenakan, radiasi yang diteruskan pada filter Al $6 \mathrm{~mm}$ lebih banyak dibanding dengan filter Al $2 \mathrm{~mm}$. Semakin tebal filter, maka radiasi sinar-X yang diteruskan semakin besar dan citra yang diperoleh akan semakin terang. Nilai ROI pada citra hasil pembacaan menggunakan software DoseLab ditampilkan di tabel 2.

Tabel 2. Data Pembacaan Nilai ROI pada citra Pesawat Sinar-X Simulator

\begin{tabular}{|c|c|c|c|c|c|}
\hline \multirow{2}{*}{$\begin{array}{l}\text { Tegangan } \\
\text { set }(\mathrm{kV})\end{array}$} & \multirow{2}{*}{$\begin{array}{c}\text { Tegangan terukur } \\
(\mathrm{kVp})\end{array}$} & \multirow[b]{2}{*}{$\%$ Error } & \multicolumn{2}{|c|}{ Tebal } & \multirow{2}{*}{$\begin{array}{l}\text { Rasio ROI } \\
\text { (S1/S2) }\end{array}$} \\
\hline & & & $\begin{array}{l}\text { Nilai ROI } \\
6 \mathrm{~mm}(\mathrm{~S} 1)\end{array}$ & $\begin{array}{l}\text { Nilai ROI } \\
2 \mathrm{~mm}(\mathrm{~S} 2)\end{array}$ & \\
\hline 60 & 57,93 & 3,4 & 324,13 & 387,03 & 0,83748 \\
\hline 65 & 62,84 & 3,3 & 358,48 & 417,86 & 0,85789 \\
\hline 70 & 67,76 & 3,2 & 382,91 & 442,54 & 0,86526 \\
\hline 75 & 72,74 & 3,05 & 413,59 & 469,93 & 0,88011 \\
\hline 80 & 77,72 & 2,9 & 441,32 & 492,86 & 0,89543 \\
\hline 85 & 82,47 & 3,0 & 462,97 & 511,00 & 0,90601 \\
\hline 90 & 87,23 & 3,1 & 483,21 & 530,06 & 0,91161 \\
\hline 95 & 92,05 & 3,1 & 505,04 & 550,16 & 0,91799 \\
\hline 100 & 96,90 & 3,1 & 521,78 & 564,82 & 0,92380 \\
\hline
\end{tabular}

Berdasarkan data pada tabel 2 diperoleh grafik hubungan antara rasio nilai ROI dari filter Al tebal $6 \mathrm{~mm}(\mathrm{~S} 1)$ dan $2 \mathrm{~mm}(\mathrm{~S} 2)$ terhadap tegangan terukur $(\mathrm{kVp})$ seperti terlihat pada gambar 3. Tegangan terukur pada $60-90 \mathrm{kV}$ diperoleh berdasarkan dari perhitungan data rata-rata tegangan pada tabel 1, sedangkan $95 \mathrm{kV}$ dan $100 \mathrm{kV}$ diperoleh berdasarkan perhitungan dari rata-rata \%error yakni sebesar $3,1 \%$. 


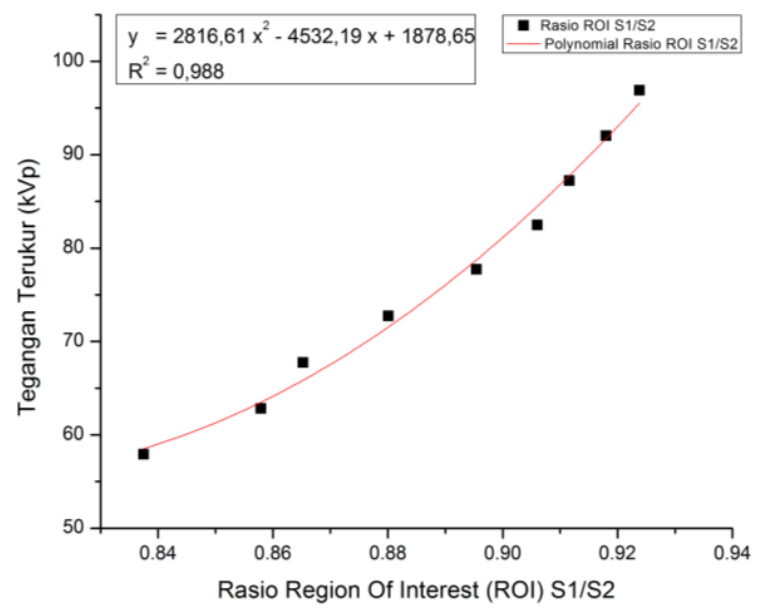

Gambar 3. Grafik Hubungan Rasio ROI (S1/S2) terhadap Tegangan terukur (kVp)

Pada gambar 3 dapat dilihat hubungan antara nilai rasio ROI pada filter Al terhadap tegangan terukur $(\mathrm{kVp})$. Nilai rasio ROI S1/S2 dengan tegangan terukur berbanding lurus. Semakin besar nilai rasio ROI S1/S2 maka tegangan yang terukur juga akan semakin besar. Hal ini dikarenakan tegangan tinggi akan menghasilkan energi sinar-X yang tinggi, sehingga daya tembus ke target juga akan semakin besar pula. Nilai rasio ROI S1/S2 pada grafik terbentuk pada kisaran 0,83 sampai 0,92 dimana nilai yang tertinggi terjadi pada tegangan terukur $96,9 \mathrm{kVp}$ dengan nilai rasio ROI 0,92. Sedangkan nilai terendah berada pada tegangan $60 \mathrm{kV}$ dengan nilai rasio ROI 0,83. Grafik hubungan antara nilai rasio ROI $\mathrm{S} 1 / \mathrm{S} 2$ terhadap tegangan terukur $(\mathrm{kVp})$ diperoleh persamaan sebagai berikut:

$$
y=2816,61 x^{2}-4532,19 x+1878,65
$$

dengan nilai $\mathrm{R}^{2}=0,988$.

Penelitian selanjutnya yaitu penyinaran dengan menggunakan pesawat sinar-X Fluoroskopi model SM-20HFH. Tegangan yang digunakan untuk melakukan penyinaran adalah $70 \mathrm{kV}$ dan $55 \mathrm{kV}$ dengan arus tetap $10 \mathrm{~mA}$ dan waktu penyinaran 1 detik. Penyinaran ini bertujuan untuk menghitung nilai $\mathrm{kVp}$ menggunakan persamaan yang diperoleh dari grafik pada gambar 3. Berikut citra yang dihasilkan pada penyinaran menggunakan pesawat sinar-X Fluoroskopi:

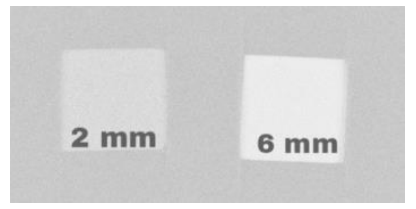

(a)

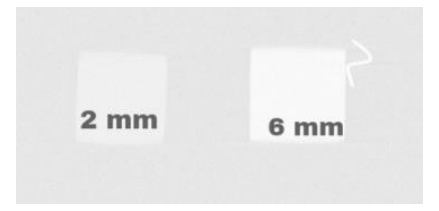

(b)

Gambar 4. Hasil citra dengan tebal filter pada penyinaran (a) $70 \mathrm{kV}$ dan (b) $55 \mathrm{kV}$ dalam arus tetap $10 \mathrm{~mA}$ dan waktu 1 detik

Nilai ROI pada gambar 4 dibaca dengan software DoseLab, hasilnya diperlihatkan di tabel 3. 
Tabel 3. Data Pembacaan Nilai ROI pada citra Pesawat Sinar-X Fluoroskopi

\begin{tabular}{cccc} 
& \multicolumn{2}{c}{ Tebal } & \\
\cline { 2 - 3 } Tegangan set $(\mathrm{kV})$ & $6 \mathrm{~mm}(\mathrm{~S} 1)$ & $2 \mathrm{~mm}(\mathrm{~S} 2)$ & \\
\hline 70 & 142,36 & 191,65 & 0,74281 \\
55 & 98,06 & 116,78 & 0,83970 \\
\hline
\end{tabular}

Berdasarkan tabel 3 nilai rasio ROI S1/S2 yang digunakan untuk menghitung $\mathrm{kVp}$ yang terukur dengan mensubtitusikan ke dalam persamaan pada (1), hasilnya diperlihatkan di tabel 4.

Tabel 4. Data Perhitungan kVp Terukur

\begin{tabular}{cccc} 
Tegangan set $(\mathrm{kV})$ & Rasio & Tegangan terukur $(\mathrm{kVp})$ & \%Error \\
\hline 70 & 0,74281 & 66,21 & 5,42 \\
55 & 0,83970 & 58,95 & $-7,18$ \\
\hline
\end{tabular}

Pada tabel 4 dapat dilihat nilai $\mathrm{kVp}$ yang terukur pada tegangan $70 \mathrm{kV}$ dan $55 \mathrm{kV}$ masingmasing adalah 66,21 dan $58,95 \mathrm{kV}$ atau memiliki nilai error masing-masing sebesar $5,42 \%$ dan $-7,18 \%$. Nilai tersebut masih berada dalam toleransi persyaratan lolos uji pesawat sinar-X Fluoroskopi, yaitu dengan error $\max \leq 10 \%$. Dengan kata lain alat tersebut dalam keadaan handal. Berdasarkan American Association of Physicist in Medicine (AAPM), nilai error hasil pengukuran $\mathrm{kVp}$ berada di luar batas toleransi yaitu $\pm 5 \%$.

Nilai error dari kedua alat pesawat sinar-X menunjukkan bahwa keluaran tegangan yang terukur masih memenuhi standar dan handal untuk digunakan, karena nilai error masih dibawah batas yang telah ditentukan yaitu $\leq 10 \%$. Pesawat sinar-X Simulator dengan pengukuran menggunakan $\mathrm{kV}$ meter langsung diperoleh akurasi tegangan yang lebih baik, dibandingkan pesawat sinar-X Fluoroskopi dengan pengukuran $\mathrm{kV}$ meter tidak langsung. $\mathrm{Hal}$ tersebut ditunjukkan pada tabel 1 pengukuran $\mathrm{kV}$ meter langsung masing-masing $\mathrm{kV}$ diperoleh nilai error yang lebih kecil dibandingkan dengan pengujian $\mathrm{kV}$ meter tidak langsung tabel 4.

\section{KESIMPULAN}

Nilai rasio ROI dari filter dengan ketebalan $6 \mathrm{~mm}$ dan $2 \mathrm{~mm}$ sebanding dengan tegangan $(\mathrm{kV})$. Semakin besar nilai rasio ROI maka tegangan yang terukur pada imaging plate juga akan semakin besar. Oleh karena itu, tegangan yang dibutuhkan untuk menembus suatu objek juga akan semakin besar, sehingga akan menghasilkan energi sinar-X yang besar. Nilai $\mathrm{kVp}$ yang terukur pada imaging plate pada penyinaran $70 \mathrm{kV}$ dengan menggunakan pesawat sinar-X Fluoroskopi adalah $66,21 \mathrm{kV}$ dan nilai error 5,41\%. Sedangkan pada penyinaran $55 \mathrm{kV}$ nilai $\mathrm{kVp}$ yang terukur adalah $58,95 \mathrm{kV}$ dengan nilai error $-7,18 \%$.

\section{DAFTAR PUSTAKA}

1 Fajrin, H. R., Rahmat, Z., \& Sukwono, D. 2019. Kilovolt Peak Meter Design As A Calibrator Of X-Ray Machine. International Journal of Electrical and Computer Engineering (IJECE), 9(4), 2328-2335. 
2 Peraturan Kepala Badan Pengawas Tenaga Nuklir No 9. 2011. Keselamatan Radiasi dalam Penggunaan Pesawat Sinar-X Radiologi Diagnostik dan Intervensional. Jakarta: BAPETEN.

3 Aryani, A. I., Nugroho, I. K., \& Nurcahyo, P. W. 2016. Pengujian Akurasi kVp Dan Linieratias Pada Pesawat Sinar-X di Laboratorium Prodi Diploma III Teknik Radiodiagnostik Dan Radioterapi Purwokerto, Journal Imaging Diagnostik, 2(2), 172174.

4 Mubarok, M. A., Yulianto., \& Indrato, B. 2018. Scintillator X-Ray kV Meter. Seminar Tugas Akhir: Politeknik Kesehatan Kementrian Kesehatan Surabaya.

5 Ulgen, Y., \& Tumer, M. 2011. Design of a Microcontroller Based and X-Ray Waveform Independent kVp-Meter. American Journal of Biomedical Engineering, 1(1), 41-43.

6 Taha, M. T. 2015. Study The Quality Assurance Of Conventional X-Ray Machine Using Non-Invasive KV Meter. International Journal Of Science And Research (IJSR). 4(3). 372-375.

7 Sartinah., Sumariyah., \& Ayu, N. 2008. Variasi Nilai Eksposi Aturan 15 Persen pada Radiografi Menggunakan Imaging Plate untuk Mendapatkan Kontras Tertinggi. Berkala Fisika, 11(2), 45-52.

8 Jannah, N., Armyanah, B., \& Abdullah B. 2014. Analisis Kurva Karakteristik Image Plate Computed Radiography (CR) Sebagai Indikator Sensitifitas Terhadap Sinar-X. Prosiding Seminar Nasional Geofisika, 200-206.

9 Shetty, C. M., Barthur, A., Kambadakone, A., Narayanan, N., \& Kv, Rajagopal. 2011. Computed Radiography Image Artifacts Revisited. American Roentgen Ray Society, 196, 37-47. 